Tobias Lüdtke, Alexander Schmidt, Caren Göbel, Anna Fischer, Nils Becker, Christoph Reimann, Thomas Bredow, Richard Dronskowski, Martin Lerch

\title{
Synthesis and Crystal Structure of $8-T a O N$, a Metastable Polymorph of Tantalum Oxide Nitride
}

\section{Article, Postprint}

This version is available at https://doi.org/10.14279/depositonce-6576.

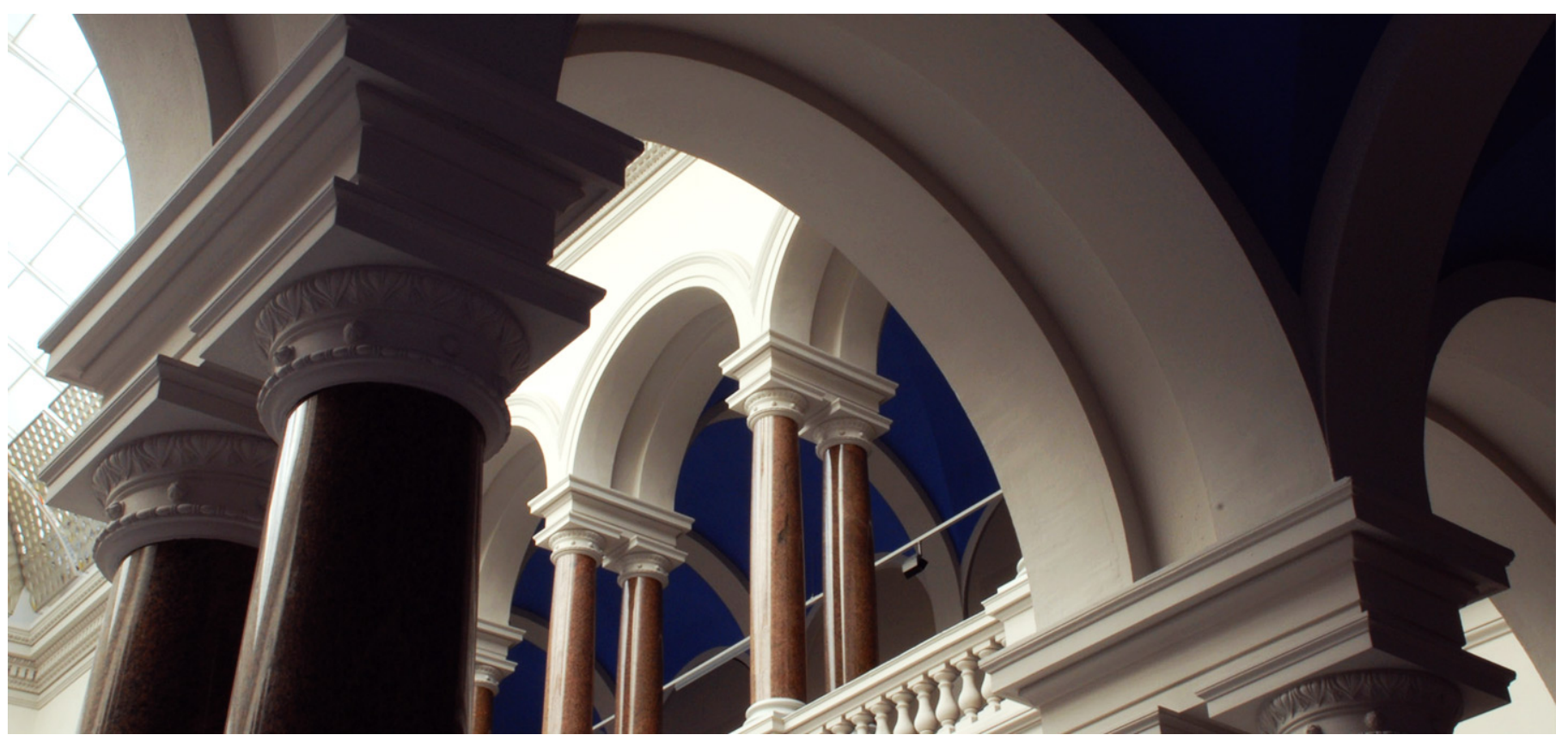

\section{Suggested Citation}

Tobias Lüdtke, Alexander Schmidt, Caren Göbel, Anna Fischer, Nils Becker, Christoph Reimann, Thomas Bredow, Richard Dronskowski, Martin Lerch: Synthesis and Crystal Structure of $\delta$-TaON, a Metastable Polymorph of Tantalum Oxide Nitride. In: Inorganic Chemistry. - ISSN: 1520-510X. - 53 (2014), 21, pp. 11691-11698. - DOI: 10.1021/ic501726m. 


\title{
Synthesis and Crystal Structure of $\delta-T a O N$, a Metastable Polymorph of Tantalum Oxide Nitride
}

\author{
Tobias Lüdtke, Alexander Schmidt, Caren Göbel, Anna Fischer, Nils Becker, \\ Christoph Reimann, Thomas Bredow, Richard Dronskowski, Martin Lerch
}

\author{
Postprint \\ Inorganic Chemistry 2014, 53(21), 11691-11698 \\ DOI: $10.1021 /$ ic501726m \\ http://pubs.acs.org/doi/abs/10.1021/ic501726m
}

Contribution to publication:

T. Lüdtke: Sample preparation, characterization, writing.
A. Schmidt: Evaluation.
C. Göbel: $\quad$ Measurements (TEM), writing.
A. Fischer: $\quad$ Measurements (TEM).
N. Becker: Quantum-chemical calculations, writing.
C. Reimann: Quantum-chemical calculations, writing.
T. Bredow: $\quad$ General discussion, proofreading.
R. Dronskowski: General discussion, proofreading.
M. Lerch: General discussion, proofreading.

Overall contribution of T. Lüdtke to the publication: $40 \%$ 
Authors. Tobias Lüdtke, ${ }^{\mathrm{a}}$ Alexander Schmidt, ${ }^{\mathrm{a}}$ Caren Göbel, ${ }^{\mathrm{a}}$ Anna Fischer, ${ }^{\mathrm{a}}$ Nils Becker, ${ }^{b, c}$ Christoph Reimann, ${ }^{d}$ Thomas Bredow, ${ }^{d}$ Richard Dronskowski, ${ }^{b, c}$ Martin Lerch ${ }^{\text {a,* }}$

(a) Institut für Chemie, Technische Universität Berlin, Straße des 17. Juni 135, D-10623 Berlin, Germany

(b) Institut für Anorganische Chemie, RWTH Aachen University, Landoltweg 1, D-52056 Aachen, Germany

(c) Jülich-Aachen Research Alliance (JARA-HPC), RWTH Aachen University, D-52056 Aachen, Germany

(d) Institut für Physikalische und Theoretische Chemie, Universität Bonn, Wegelerstraße 12, D-53115 Bonn, Germany

* Corresponding author

Keywords. Tantalum; Oxide nitrides; N/O order; Anatase; Quantum-chemical calculations

Dedication. Dedicated to Dr. Hans Boysen on the occasion of his $70^{\text {th }}$ birthday.

Supporting Information. Crystallographic data in CIF format for the structure refinement of $\delta$-TaON. Table with Gaussian-type basis sets for Ta, $\mathrm{O}$, and N. This material is available free of charge via the Internet at http://pubs.acs.org.

Received: $\quad$ 06.08.2014

Accepted: $\quad 29.09 .2014$

Published online: 13.10.2014

Reprinted (adapted) with permission from Lüdtke, T.; Schmidt, A.; Göbel, C.; Fischer, A.; Becker, N.; Reimann, C.; Bredow, T.; Dronskowski, R.; Lerch, M. Synthesis and Crystal Structure of $\delta$-TaON, a Metastable Polymorph of Tantalum Oxide Nitride. Inorg. Chem. 2014, 53(21), 11691-11698. Copyright (2014) American Chemical Society. 


\subsection{Abstract}

$\delta$ - $\mathrm{TaON}$ was prepared by reaction of gaseous ammonia with an amorphous tantalum oxide precursor. As a representative of the anatase structure (aristotype) it crystallizes in the tetragonal crystal system with lattice parameters $a=391.954(16) \mathrm{pm}$ and $c=1011.32(5) \mathrm{pm}$. At temperatures between 1073 and $1123 \mathrm{~K}$ an irreversible phase transformation to baddeleyite-type $\beta-\mathrm{TaON}$ is observed. While quantum-chemical calculations confirm the metastable character of $\delta$ - $\mathrm{TaON}$, its transformation to $\beta-\mathrm{TaON}$ is kinetically controlled. The anion distribution of the anatase-type phase was studied theoretically. In agreement with previous studies, it was found that a configuration with maximal $\mathrm{N}-\mathrm{N}$ distances is most stable. The calculated band edge energies indicate that $\delta$-TaON is a promising photocatalytic material for redox reactions, e.g., water splitting.

\subsection{Introduction}

Transition metal oxide nitrides are a group of materials which attracted a lot of attention in recent years. In particular, tantalum-based compounds are, for example, suitable as nontoxic color pigments, ${ }^{1,2}$ can be considered as fast ion conductors, ${ }^{3}$ and are used as materials for photocatalytical water splitting under sunlight. ${ }^{4,5}$ From a thermodynamical point of view, the most stable polymorph of tantalum oxide nitride is the so-called $\beta$-phase, reported first by Brauer and Weidlein. ${ }^{6}$ It crystallizes in the well-known monoclinic baddeleyite-type structure also reported for $\mathrm{ZrO}_{2}$ and exhibits a bright yellow color (optical band gap of ca. $2.6 \mathrm{eV}$ ). A metastable polymorph $(\gamma-\mathrm{TaON})$ was reported by Schilling et al. ${ }^{7}$ It shows an orange color (optical band gap of ca. $2.15 \mathrm{eV}$ ) and crystallizes similar to $\mathrm{VO}_{2}(\mathrm{~B})$ in the monoclinic crystal system. For both $\beta$ - and $\gamma-\mathrm{TaON}$, an ordered distribution of oxygen and nitrogen was found. Another polymorph, $\alpha-\mathrm{TaON}$, was suggested by Buslaev et al. ${ }^{8}$ but disproved by quantum-chemical calculations. ${ }^{9}$ A possible high-pressure modification was predicted independently by two different groups. ${ }^{10,11}$ Pressures of more than ca. $31 \mathrm{GPa}$ should induce a phase transformation from $\beta$-TaON (7-fold coordination of $\mathrm{Ta}$ ) to a cotunnite-type structure with 9-fold coordinated cations. In fact, this cotunnite phase has recently been found by high-pressure studies, ${ }^{12}$ just as predicted. In addition, the relative stabilities of various structure types (including the anatase, rutile, and fluorite type) were calculated by quantum-chemical methods a couple of years ago. ${ }^{13}$ Interestingly, and in clear contrast to $\mathrm{TiO}_{2}$, the anatase type is energetically favored compared to the rutile type. With the small calculated stability difference of only 
ca. $20 \mathrm{~kJ} \cdot \mathrm{mol}^{-1}$ between baddeleyite (most stable) and anatase type, ${ }^{13}$ it is worth the effort trying to synthesize anatase-type $\mathrm{TaON}$.

It should be mentioned that anatase-type phases have previously been prepared by incorporating lower-valent cations such as $\mathrm{Mg}^{2+14}$ or $\mathrm{Sc}^{3+15}$ into TaON. In particular, substitution of 5\% tantalum by magnesium leads to a phase-pure material with the composition $\mathrm{Mg}_{0.05} \mathrm{Ta}_{0.95} \mathrm{O}_{1.15} \mathrm{~N}_{0.85}$. This was the first example of an anatase-type structure not containing the element titanium. Interestingly, the preparation of 30-45 nm thin films of undoped anatase-type $\mathrm{TaON}$ on $\left(\mathrm{LaAlO}_{3}\right)_{0.3}\left(\mathrm{SrAl}_{0.5} \mathrm{Ta}_{0.5} \mathrm{O}_{3}\right)_{0.7}$ (LSAT) single crystals using nitrogen plasma-assisted pulsed laser deposition (NPA-PLD) was recently reported by Suzuki et al. ${ }^{16}$ Epitaxial stress from the substrate stabilizes the anatase-type structure without additional elements such as magnesium or scandium. From a photocatalytical point of view, this material is of great interest due to its optical band gap of $c a .2 .4 \mathrm{eV}$ and its high charge carrier mobility which is comparable to that of anatase-type $\mathrm{TiO}_{2}{ }^{16}$ Unfortunately, the quality of the X-ray diffraction patterns of the films is insufficient for a real structural refinement including atomic positions, bond lengths, etc. In the present Article we report, for the first time, the synthesis and crystal structure of tantalum oxide nitride powder with anatase-type structure without any additional cations. From now on we call this the $\delta-\mathrm{TaON}$ phase.

\subsection{Experimental Section}

Synthesis. Amorphous tantalum oxide precursors were prepared via a modified Pechini route. ${ }^{17}$ Tantalum chloride (99.999\%, Alfa Aesar) was solved in an ethanol-citric acid solution. Citric acid was used in a molar excess of 12 times the $\mathrm{TaCl}_{5}$. Ethylene glycol in a molar excess of 17 times the tantalum chloride was added for the gelling process. Ethanol, $\mathrm{HCl}$, and water, the latter formed during the esterification, are evaporated at ca. $423 \mathrm{~K}$. The polymerization can be finalized by heating the mixture to $473 \mathrm{~K}$. The material was calcined at $673 \mathrm{~K}$ for $40 \mathrm{~h}$. The products were colorless X-ray amorphous powders. The maximum yield of $43 \mathrm{wt} \%$ of anatase-type tantalum oxide nitride was obtained by ammonolysis of these amorphous precursors at $1033 \mathrm{~K}$, a reaction time of $1 \mathrm{~h}$, and flow rates of $12.50 \mathrm{~L} \cdot \mathrm{h}^{-1}$ ammonia and $0.02 \mathrm{~L} \cdot \mathrm{h}^{-1}$ oxygen. Additional phases were $\beta$-TaON, $\gamma$-TaON, and $\mathrm{Ta}_{3} \mathrm{~N}_{5}$. Samples without $\gamma$-phase could be obtained using an increased ammonia flow rate of $23.75 \mathrm{~L} \cdot \mathrm{h}^{-1}$, while the other parameters were unaltered. For the investigation of the high-temperature behavior in inert atmosphere the samples were heated at different temperatures for $1 \mathrm{~h}$ in closed copper capsules (nitrogen atmosphere). 
After cooling down to ambient temperature the phase fractions were determined by X-ray diffraction.

Characterization. A PANalytical X'Pert Pro powder diffractometer ( $\mathrm{Cu}-K_{\alpha}$ radiation) was used for XRD measurements. Rietveld refinements including quantitative phase analyses were carried out using the program FULLPROF 2000. ${ }^{18}$ Profiles were fitted with a pseudo-Voigt function.

The contents of nitrogen and oxygen were determined by hot gas extraction using a LECO TC-300/EF-300 N/O analyzer. $\mathrm{ZrO}_{2}$ and steel were used as standard materials. The accuracy is ca. $2 \%$ of the $\mathrm{N} / \mathrm{O}$ contents present. X-ray fluorescence spectrometry (XRF) was performed using a PANalytical Axios spectrometer with an Rh-tube. Crystallinity, phase composition (identification of $\delta-\mathrm{TaON}, \beta-\mathrm{TaON}, \mathrm{Ta}_{3} \mathrm{~N}_{5}$ ), and morphology of the particles were investigated by high-resolution transmission electron microscopy (HRTEM), selected area electron diffraction (SAED), and energy dispersive X-ray spectroscopy (EDX) analysis. For TEM analysis, powder samples were deposited on a holey carbon coated nickel grid. TEM and HRTEM measurements were performed at the Department of Electron Microscopy of the TU Berlin (ZELMI) on a Tecnai $G^{2}$ S-Twin transmission electron microscope (FEI Company, Eindhoven, Netherlands) equipped with a $\mathrm{LaB}_{6}$-source operated at $200 \mathrm{kV}$. Images were recorded with a GATAN MS794 P CCD-camera. EDX-analysis were carried out with an r-TEM SUTW Detector from $\operatorname{EDAX}(\mathrm{Si}(\mathrm{Li})$-detector).

Quantum-Chemical Calculations. In order to investigate the thermodynamic properties of the TaON phases, periodic density functional theory (DFT) calculations were performed as implemented in the Vienna ab initio simulation package (VASP). ${ }^{19,20}$ Projectoraugmented waves (PAW $)^{21}$ were used to separate the core and valence electrons. Exchange and correlation contributions were treated within the generalized-gradientapproximation as described by Perdew, Burke, and Ernzerhof (GGA-PBE). ${ }^{22}$ An energycutoff of $500 \mathrm{eV}$ and a Monkhorst-Pack $k$-point mesh of $20 \times 20 \times 8$ were used for structure optimization, and ensured convergence.

Quasiharmonic phonon calculations were performed using the program PHONOPY. ${ }^{23}$ In a first step, a supercell was constructed on the basis of the optimized crystal structure. All symmetry-inequivalent atoms of the previously created supercell were then slightly 
shifted out of their equilibrium position to calculate the Hellman-Feynman forces. Subsequently, the force constants and then the dynamical matrix were computed. With a combination of its eigenvalues (phonon frequencies) with Bose-Einstein statistics, the free phonon energy was obtained. ${ }^{24}$ Thermodynamic properties at finite temperatures are straightforwardly accessible from these data.

For the investigation of the high-pressure behavior, the cell volume was varied by scaling the cell parameters between 0.94 and 1.04 (with a fixed $a: b: c$ ratio and rectangular cell angles). The resulting energy versus volume data were fitted to the BirchMurnaghan equation of state. ${ }^{25}$ Thus, the pressure and, eventually, reaction enthalpies as a function of the pressure were calculated.

In order to investigate the dependence of the calculated properties on the basis set and functional, additional periodic calculations employing the PBE functional as well as the PBE026 DFT-Hartree-Fock hybrid method were conducted with the CRYSTAL program package (C09) ${ }^{27}$ We used atom-centered Gaussian basis sets of valence double- $\zeta$ quality that have been optimized especially for the use in solid-state calculations (exponents and coefficients are listed in the Supporting Information, Chapter 4.8). For tantalum an effective core potential was employed (SD60MWB28) so that a total number of 13 electrons were kept in the semicore and valence region of each $\mathrm{Ta}$ atom, while all-electron basis sets were used for oxygen and nitrogen. The default values for the integral accuracy in CRYSTAL 09 have been increased by a factor of 10, and Monkhorst-Pack and Gilat grids have been generated using the shrinking factors $(8,8)$. In order to obtain the Gibbs energies of the $\mathrm{TaON}$ polymorphs we performed frequency calculations at the $\Gamma$ point. ${ }^{29,30}$ Furthermore, we calculated the bulk modulus for the new phase by fitting the results of constant volume optimizations against the third-order isothermal Birch-Murnaghan's equation of state.

For the determination of the absolute electronic band edge positions with respect to the vacuum we performed periodic slab calculations with the PBE as well as the PBE0 functional. Since the Kohn-Sham gap as obtained from the PBE calculations is not a good approximation to the optical gap in solids, ${ }^{31}$ we will follow the approach of Caspary Toroker et al. and merely calculate the band gap center from the hybrid calculations. ${ }^{32} \mathrm{It}$ has been shown that the band gap center is reproduced more reliably within the KohnSham approach than the valence band maximum. ${ }^{33}$

In order to calculate the optical excitations, we employed the Bethe-Salpeter approach. ${ }^{34}$ Therefore, we first calculated the quasiparticle gap with the GW0 method using 
the VASP code. ${ }^{35-38}$ The computational setup for these surface calculations has been described in detail elsewhere. ${ }^{39}$ For these calculations, we used small-core PAWs developed for GW calculations as supplied with the VASP program package. In order to reduce the computational demands, a smaller Monkhorst-Pack $k$-point grid $(6 \times 6 \times 6)$ has been chosen as well as a lower energy cutoff $(400 \mathrm{eV})$ compared to the structure relaxations. Increasing these values in test calculations did not alter the results significantly.

\subsection{Results and Discussion}

The synthetic conditions, described in the Experimental Section, had to be respected carefully. Slightly increased reaction temperatures (e.g., $1043 \mathrm{~K}$ instead of $1033 \mathrm{~K}$ ) strongly preferred the formation of $\mathrm{Ta}_{3} \mathrm{~N}_{5}$, while at lower temperatures (for example $1023 \mathrm{~K})$ large parts of the amorphous tantalum oxide precursor did not react with ammonia but partially crystallized to $\beta-\mathrm{Ta}_{2} \mathrm{O}_{5}$. As mentioned above, we were successful in obtaining samples with a yield up to $43 \mathrm{wt} \%$ of the new $\delta$-TaON polymorph as best result. With respect to the difficulties in refining the crystal structure of the disordered $\gamma$-phase, ${ }^{7}$ we decided to choose a sample with a slightly smaller fraction of $\delta$-TaON but without any $\gamma$-TaON for the Rietveld refinement. The red color of all prepared samples is likely dominated by the presence of dark-red $\mathrm{Ta}_{3} \mathrm{~N}_{5}$. The red color also points to the $\mathrm{ab}$ sence of significant amounts of reduced tantalum resulting in black samples. XRF analysis proved the absence of other elements than tantalum, oxygen, and nitrogen.

Figure 4.1 presents the experimental powder XRD pattern with the results of the Rietveld refinement. Details are given in Table 4.1. The sample consists of three crystalline phases: anatase-type $\delta$ - $\mathrm{TaON}$ (35 wt \%), $\mathrm{Ta}_{3} \mathrm{~N}_{5}$ (45 wt \%), and baddeleyite-type $\beta$-TaON $(20 \mathrm{wt} \%)$. This is in good agreement with the results of chemical analysis $(\mathrm{N}=7.6 \mathrm{wt} \%, \mathrm{O}=6.1 \mathrm{wt} \%)$, taking into account an additional content of amorphous tantalum oxide (assuming an overall content of $13 \mathrm{wt} \%$ amorphous $\mathrm{Ta}_{2} \mathrm{O}_{5}$ for the calculation gives the values from chemical analysis).

Additional TEM-investigations revealed that the sample consists of agglomerated crystalline nanoparticles assembled in sponge-like structures (Figure 4.2). Electron diffraction at those agglomerates as well as HRTEM analysis (see filtered images and corresponding FFT) of single nanoparticles revealed the presence of homogeneously intergrown $\delta$ - $\mathrm{TaON}, \mathrm{Ta}_{3} \mathrm{~N}_{5}$, and $\beta$-TaON particles on the nanometer scale $(20-50 \mathrm{~nm}$ particle size, Figure 4.3). While $\delta-\mathrm{TaON}$ and $\mathrm{Ta}_{3} \mathrm{~N}_{5}$ are present as rounded "sintered" parti- 


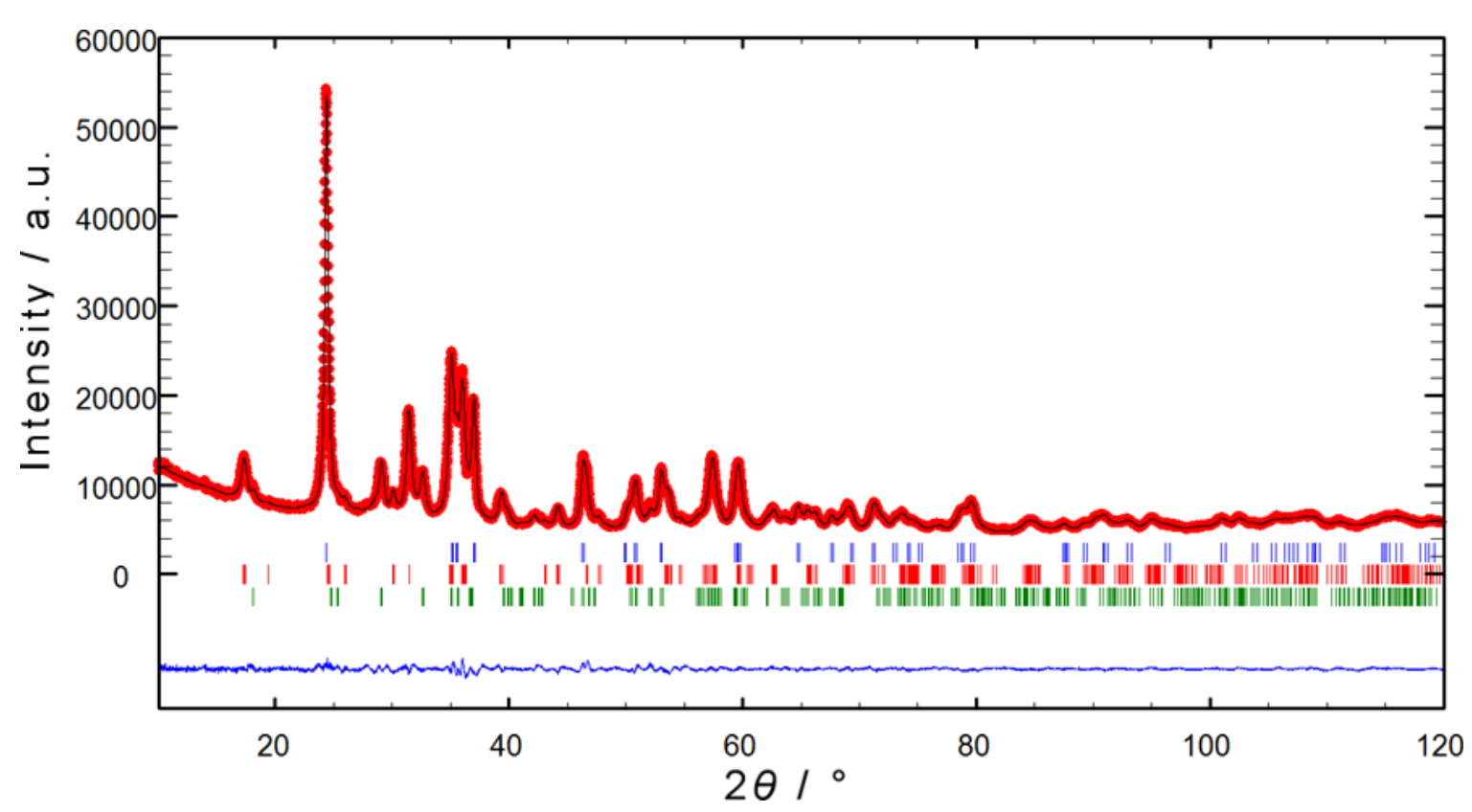

Figure 4.1. X-ray powder diffraction pattern ( $\mathrm{Cu}-K_{\alpha}$ radiation) with results of the Rietveld refinement (red: measured; black: calculated; blue: measured calculated). The vertical bars indicate the reflection positions of anatasetype $\delta$-TaON (top, blue), $\mathrm{Ta}_{3} \mathrm{~N}_{5}$ (middle, red), and $\beta-\mathrm{TaON}$ (bottom, green).*

cles, $\beta$-TaON tends also to form angular aggregates. Unfortunately EDX analysis of single particles of identified phases could not be performed, due to intergrowth/overlapping of the nanoparticles. The observed overall ratio $\mathrm{N} / \mathrm{O}$ of 1.23 is in very good agreement with the above-presented results of the chemical analysis $(\mathrm{N} / \mathrm{O}=1.24)$.

In comparison to $\mathrm{Mg}_{0.05} \mathrm{Ta}_{0.95} \mathrm{O}_{1.15} \mathrm{~N}_{0.85}$, the lattice parameters determined for $\delta$ - $\mathrm{TaON}$ have very similar values (see Table 4.1). This can be easily explained by the similar ionic radii and the small amount of $\mathrm{Mg}^{2+}$ in the doped phase. In contrast, the calculated density of the undoped material is significantly larger due to the low mass of magnesium. It is remarkable that the density of the more stable $\gamma-\mathrm{TaON}$ phase $\left(8.64 \mathrm{~g} \cdot \mathrm{cm}^{-3}\right)$ is clearly smaller which comes from the special structural features of the $\mathrm{VO}_{2}(\mathrm{~B})$ type (huge tunnels, etc., ref. 7). 
Table 4.1. Results of the Rietveld refinement for $\delta$-TaON in comparison with selected results for $\mathrm{Mg}_{0.05} \mathrm{Ta}_{0.95} \mathrm{O}_{1.15} \mathrm{~N}_{0.85}$.

\begin{tabular}{lll}
\hline & $\delta$-TaON & $\mathrm{Mg}_{0.05} \mathrm{Ta}_{0.95} \mathrm{O}_{1.15} \mathrm{~N}_{0.85}{ }^{13}$ \\
\hline Structure type & Anatase & Anatase \\
Space group & $I 41 /$ amd $(\mathrm{No.} 141)$ & $I 4_{1} /$ amd $(\mathrm{No} .141)$ \\
Crystal system & Tetragonal & Tetragonal \\
$a / \mathrm{pm}$ & $391.954(16)$ & $391.986(6)$ \\
$c / \mathrm{pm}$ & $1011.32(5)$ & $1011.19(3)$ \\
$c / \mathrm{a}$ & 2.58 & 2.58 \\
$V / 10^{6} \mathrm{pm}^{3}$ & $155.367(12)$ & $155.373(6)$ \\
$Z$ & 4 & 4 \\
$\rho_{\text {calc }} / \mathrm{g} \cdot \mathrm{cm}^{-3}$ & $9.02 \mathrm{~g} \cdot \mathrm{cm}^{-3}$ & $8.71 \mathrm{~g} \cdot \mathrm{cm}^{-3}$ \\
Diffractometer & $\mathrm{PANalytical} \mathrm{X}$ Pert Pro & \\
$2 \theta /{ }^{\circ}$ & $10-120$ & \\
$\lambda / \mathrm{pm}$ & $154.060,154.443$ & \\
& $I\left(\lambda_{2}\right) / I\left(\lambda_{1}\right)=0.5$ & \\
Profile points & 8839 & \\
$R_{\text {wp }}$ & 0.0202 & \\
$R_{\text {exp }}$ & 0.0115 & \\
$R_{\text {Bragg }}$ & 0.0141 & \\
$S$ & 1.75 & \\
\hline
\end{tabular}
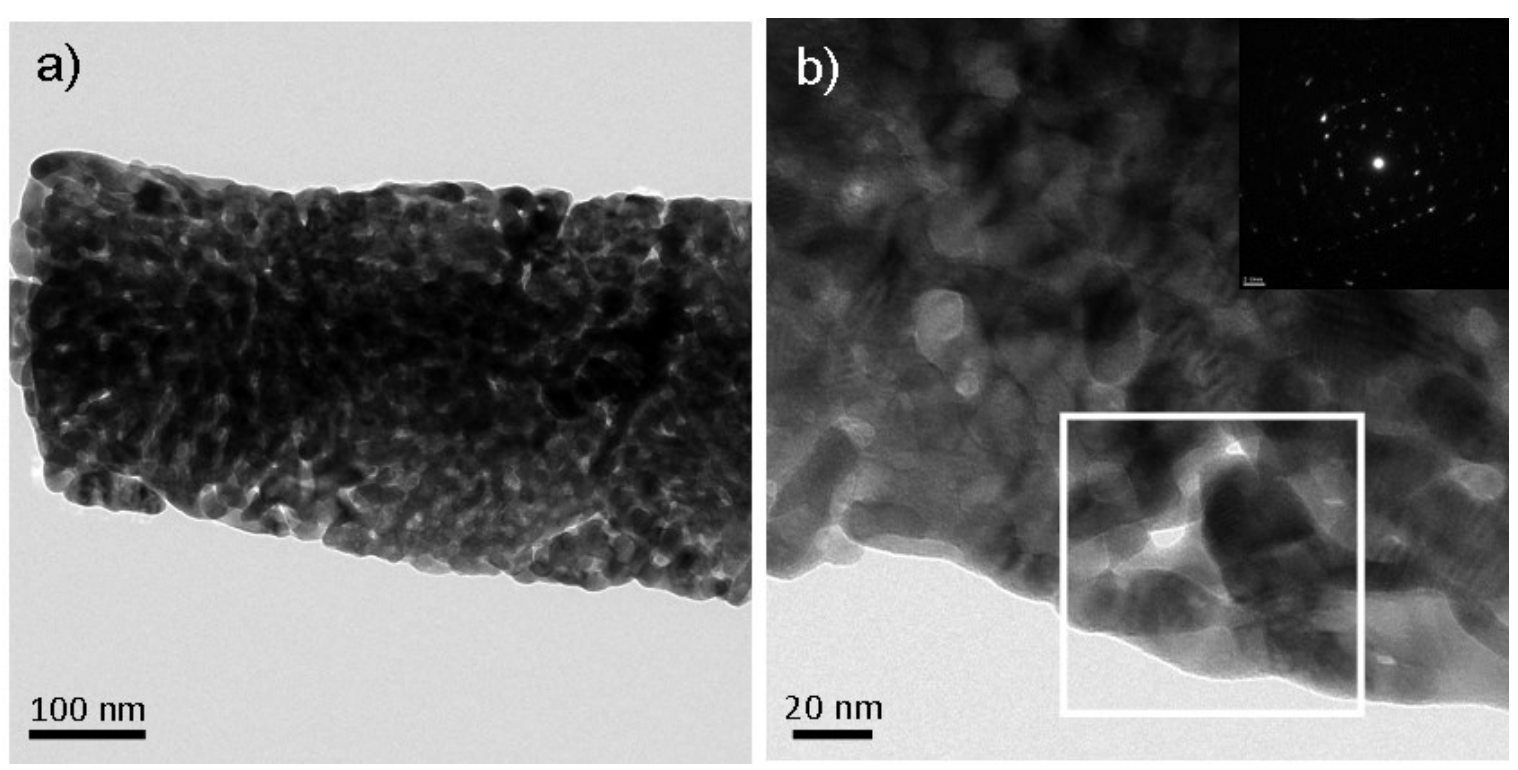

Figure 4.2. TEM-images of the as synthesized sample containing $\delta$-TaON, $\beta-\mathrm{TaON}$ and $\mathrm{Ta}_{3} \mathrm{~N}_{5}: \mathrm{a}$ ), b) porous sponge-like structure. SAED pattern given as inset, demonstrate the presence of multiple crystal phases. 

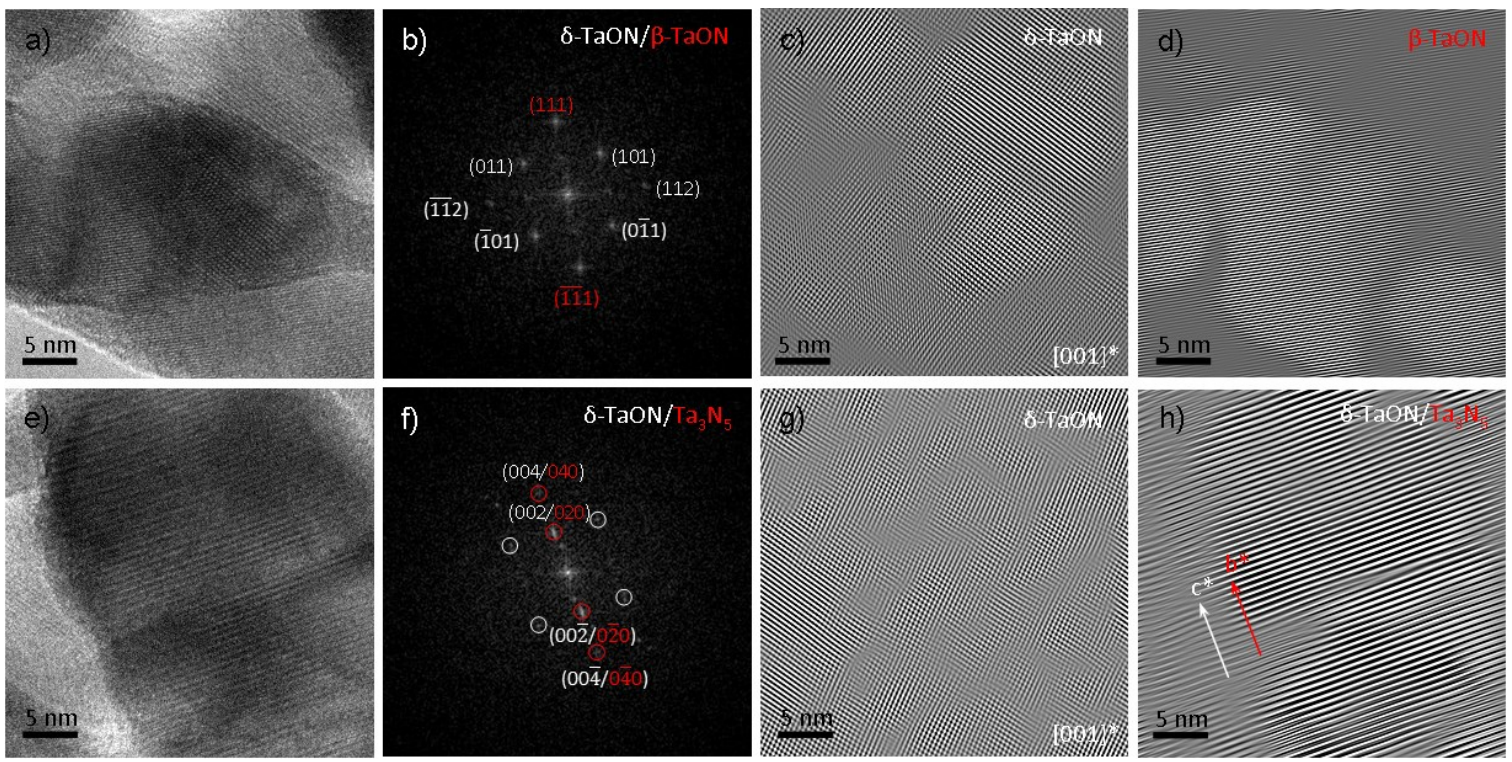

Figure 4.3. HRTEM-images (a,e) from the marked region in Figure 5.2 with corresponding FFT patterns $(\mathrm{b}, \mathrm{f})$. Filtered HRTEM-images of $(\mathrm{a})$ evidencing the presence of $\delta$-TaON (c) and $\beta$-TaON (d) and filtered HRTEM-images of (e) evidencing the presence of $\delta-\mathrm{TaON}(\mathrm{g})$ and $\mathrm{Ta}_{3} \mathrm{~N}_{5}(\mathrm{~h})$.

The refined atomic parameters are presented in Table 4.2. The isotropic DebyeWaller factors were fixed to the results acquired from neutron diffraction experiments on the $\mathrm{Mg}$ containing phase. ${ }^{14}$ Anatase-type $\mathrm{TiO}_{2}$, which is structurally characterized by $\mathrm{TiO}_{6}$-octahedra sharing four edges with neighboring octahedra and channels along the $a$ and $b$-axes, crystallizes in the tetragonal crystal system in space group $I 4_{1} /$ amd (No. 141). Using this space group for the refinement of $\delta$-TaON does not give the opportunity to respect an ordered arrangement of nitrogen and oxygen. In our case this is not a real problem because $\mathrm{X}$-ray diffraction experiments do not allow distinguishing between these elements (ions with the same number of electrons).

Table 4.2. Refined atomic parameters for anatase-type TaON.

\begin{tabular}{lllllll}
\hline Atom & Wyckoff & $x$ & $y$ & $z$ & S.O.F. $^{\mathrm{a}}$ & $B_{\text {iso }} / 10^{4} \mathrm{pm}^{2}$ \\
\hline $\mathrm{Ta}$ & $4 b$ & 0 & $1 / 4$ & $3 / 8$ & 1 & $1.3^{\mathrm{b}}$ \\
$\mathrm{O} / \mathrm{N}^{\mathrm{c}}$ & $8 e$ & 0 & $1 / 4$ & $0.5789(7)$ & $0.5 / 0.5$ & $1.4^{\mathrm{b}}$ \\
\hline
\end{tabular}

${ }^{\text {a }}$ Site occupation factor.

${ }^{\mathrm{b}}$ Fixed to the results from neutron diffraction, ref. 14 .

${ }^{\mathrm{c}}$ Not refined independently. 


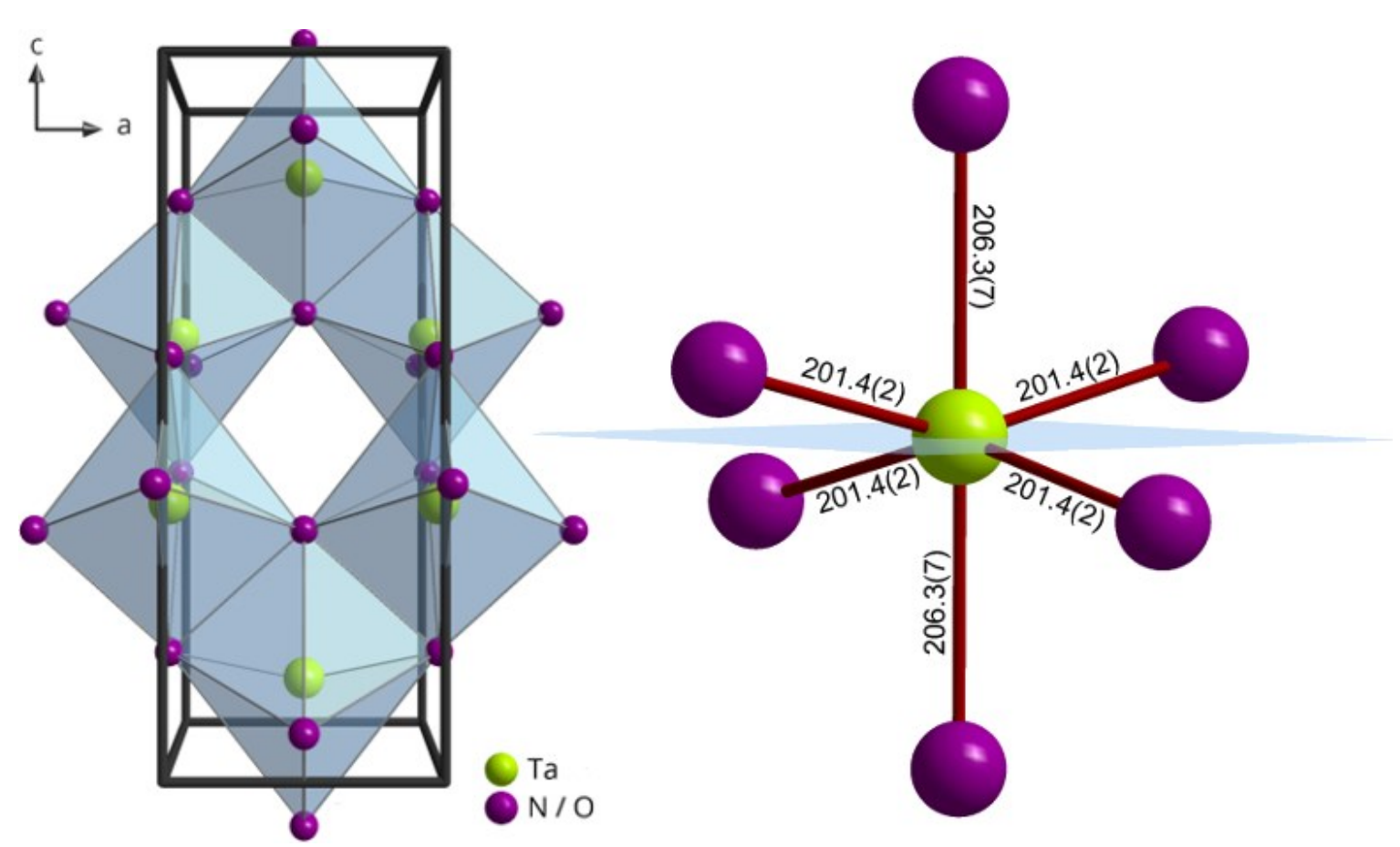

Figure 4.4. Crystal structure of anatase-type TaON. Left: unit cell with coordination octahedra. Right: Ta-O/N bond lengths in pm.*

Figure 4.4 depicts the crystal structure of anatase-type TaON with the abovementioned aristotype setting with just one kind of anion position. The calculated bond lengths of the octahedra are also presented in Figure 4.4 and are in good agreement with the ionic radii expected from the corresponding ions ${ }^{40}$ and that of $\mathrm{Mg}_{0.05} \mathrm{Ta}_{0.95} \mathrm{O}_{1.15} \mathrm{~N}_{0.85}{ }^{14}$ Possible anion arrangements have already been studied theoretically on a quantumchemical level ${ }^{13}$ and experimentally using $\mathrm{Mg}_{0.05} \mathrm{Ta}_{0.95} \mathrm{O}_{1.15} \mathrm{~N}_{0.85}{ }^{14,41}$ with consistent results. There are three maximal non-isomorphic subgroups (all translationengleich) providing two nonequivalent anion sites: $I \overline{4} m 2$ (No. 119), I4 ${ }_{1} \mathrm{md}$ (No. 109), and Imma (No. 74). It was shown that space group $I 4_{1} m d$ is the most preferred for tantalum oxide nitrides with anatase-type structure. Unfortunately, the amount of material (ca. $100 \mathrm{mg}$ ) is hitherto not sufficient for a neutron diffraction investigation which is the method of choice for the experimental determination of the N/O distribution. Larger amounts of material and an increase of the fraction of the $\delta$-phase are in the focus of our work in the near future.

The effect of different $\mathrm{N} / \mathrm{O}$ configurations in the conventional unit cell of $\delta$-TaON has already been investigated using periodic quantum-chemical calculations. ${ }^{13}$ Since we used different density functionals in this work, we nevertheless performed structure re- 


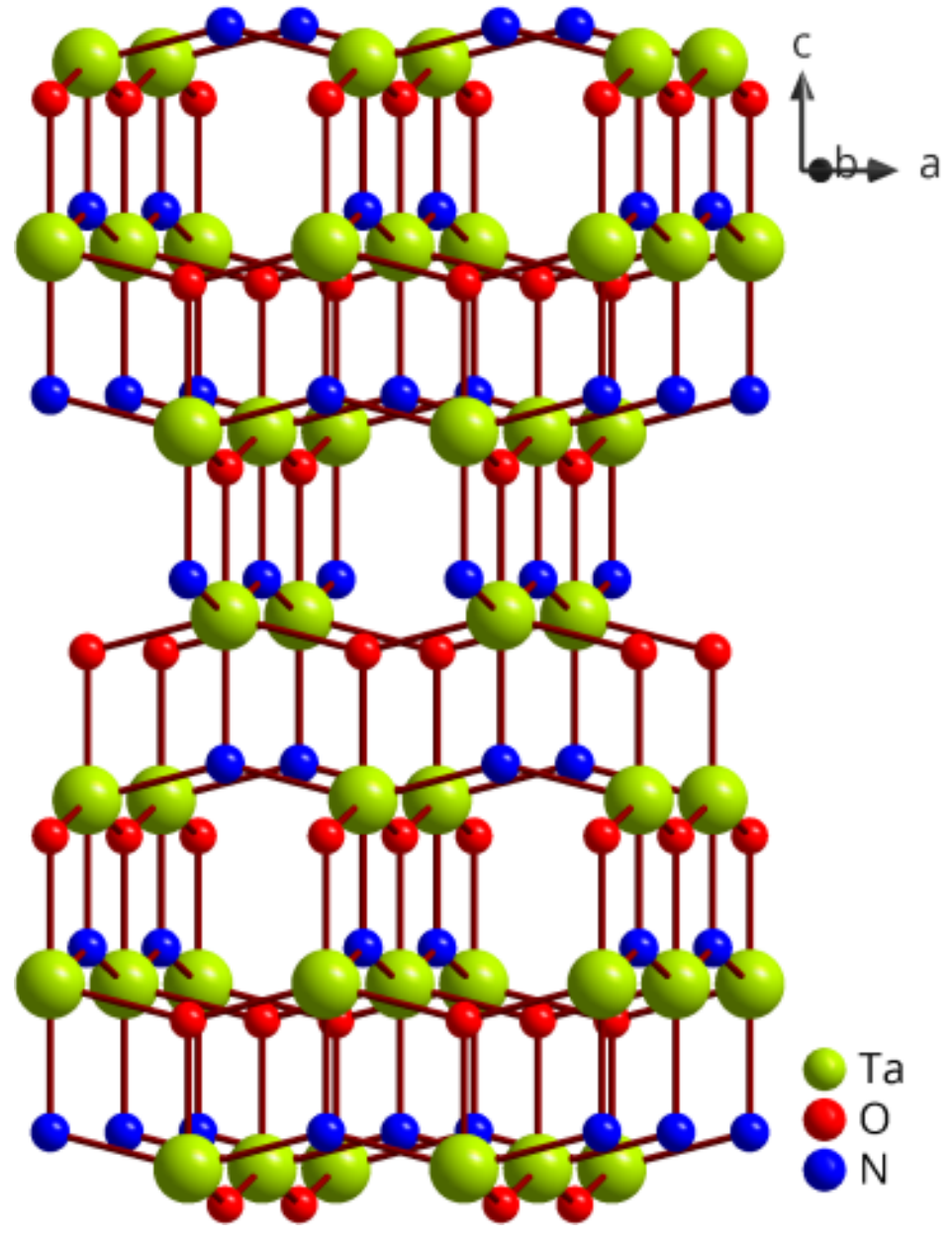

Figure 4.5.

Supercell of $\delta$ - $\mathrm{TaON}$ with the most stable N/O distribution. $^{*}$

laxations at the GGA (PBE) and DFT-HF hybrid (PBE0) level for different distributions of $\mathrm{N}$ and $\mathrm{O}$ atoms over the $8 e$ Wyckoff position. With both functionals, almost identical results were obtained that confirm the previously found structure. In the most stable configuration, $\mathrm{N}-\mathrm{Ta}-\mathrm{N}$ and $\mathrm{O}-\mathrm{Ta}-\mathrm{O}$ chains in $a$ or $b$ direction alter along the $c$ direction (see Figure 4.5). This crystal structure can be described in the space group $I 4_{1} m d$ (No. 109) with all atoms residing on the Wyckoff position $4 a$ (VASP/PBE: Ta: 0,0,0.5; O: 0,0,0.299; N: 0,0,0.701).

The relative stability of the different anatase-type phases with respect to each other is linked to the $\mathrm{N}-\mathrm{N}$ distance. In the most stable phase with $I 4_{1} m d$ symmetry, two $\mathrm{N}^{3-}$ ions are separated by at least $323 \mathrm{pm}$. In all other configurations under consideration the smallest $\mathrm{N}-\mathrm{N}$ distance was reduced by more than $8 \%$ compared to this value, which leads to energy differences up to $24 \mathrm{~kJ} \cdot \mathrm{mol}^{-1}$ per TaON formula unit due to the larger Coulomb repulsion between the $\mathrm{N}^{3-}$ anions. Nevertheless a large number of anion configurations were higher in energy by only $5-10 \mathrm{~kJ} \cdot \mathrm{mol}^{-1}$ and might thus be accessible at the 

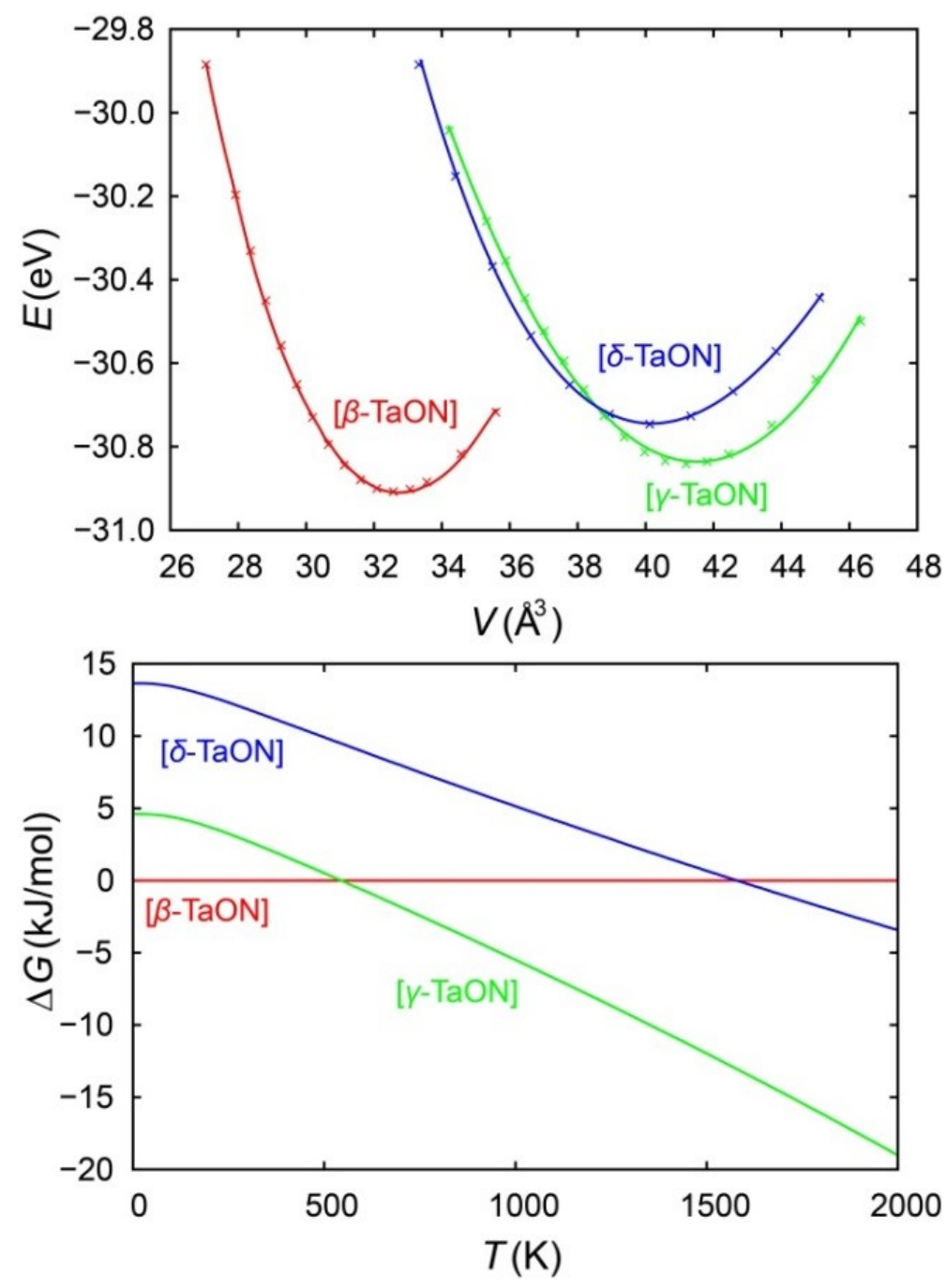

Figure 4.6.

Energy per formula unit versus volume of the three known phases of $\mathrm{TaON}$ at ambient pressure (top), and relative Gibbs energy versus temperature for the different $\mathrm{TaON}$ phases (VASP/PBE) (bottom).

applied conditions during the synthesis. The theoretical $\mathrm{Ta}-\mathrm{O} / \mathrm{N}$ bond lengths differ from the experimentally assigned values as the octahedral coordination is more strongly distorted due to the reduced symmetry. At the PBE0 level we found a single short Ta-N $(d=195 \mathrm{pm})$ and two Ta-O bond lengths $(d=197 \mathrm{pm})$, two $\mathrm{N}$ atoms $(d=205 \mathrm{pm})$ at intermediate distances, and one $\mathrm{O}$ atom with a greater displacement $(d=232 \mathrm{pm})$. The slightly shorter $\mathrm{Ta}-\mathrm{N}$ bond lengths as compared to $\mathrm{Ta}-\mathrm{O}$ nicely reflect the larger covalency in the Ta-N combination, as also found in other studies. ${ }^{42}$

In order to compare $\delta$-TaON with the well-known $\beta$ - and $\gamma$-phases, the energy per formula unit was plotted against the cell volume (Figure 4.6, VASP/PBE). Anatase-type $\mathrm{TaON}$ is energetically less favored than the thermodynamically stable baddeleyite-type by about $0.18 \mathrm{eV}$ whereas the $\mathrm{VO}_{2}(\mathrm{~B})$-type is less stable by only $0.07 \mathrm{eV}$. 
From the constant volume optimizations, we calculated the bulk moduli for the three phases from the Birch-Murnaghan equation of state. The value for $\beta-\mathrm{TaON}$ $\left(B^{\mathrm{PBE}}=259 \mathrm{GPa}, B^{\mathrm{PBE} 0}=286 \mathrm{GPa}\right)$ is in good agreement with the results from earlier theoretical work $\left(G^{\mathrm{LDA}}=280 \mathrm{GPa},{ }^{43} B^{\mathrm{PW} 91}=278 \mathrm{GPa}^{44}\right)$, whereas the previously calculated bulk modulus for the more open $\gamma$-TaON $\left(B^{\mathrm{VASP}-\mathrm{PBE}}=181 \mathrm{GPa}\right)$ is less wellreproduced using atom-centered basis functions $\left(B^{\mathrm{PBE}}=210 \mathrm{GPa}, B^{\mathrm{PBE} 0}=227 \mathrm{GPa}\right)$. For $\delta$-TaON we find a lower value compared to the other TaON phases $\left(B^{\mathrm{PBE}}=186 \mathrm{GPa}\right.$, $\left.B^{\mathrm{PBE} 0}=216 \mathrm{GPa}\right)$.

Metastable polymorphs, according to the Ostwald-Volmer rule, are usually characterized by low densities and transform to stable modifications at elevated temperatures. ${ }^{45}$ These empirical findings are apparent in Figure 4.6 where $\delta$-TaON phase has a larger volume per formula unit than $\beta-\mathrm{TaON}$. At the same time, $\gamma-\mathrm{TaON}$ which is more stable than the $\delta$-phase has a slightly smaller density [C09/PBE0: $\rho(\gamma-\mathrm{TaON})=8.6 \mathrm{~g} \cdot \mathrm{cm}^{-3}$, $\left.\rho(\delta-\mathrm{TaON})=8.9 \mathrm{~g} \cdot \mathrm{cm}^{-3}\right]$. Both values are in good agreement with the experimental results $\left[\rho(\gamma-\mathrm{TaON})=8.6 \mathrm{~g} \cdot \mathrm{cm}^{-3}, \rho(\delta-\mathrm{TaON})=9.0 \mathrm{~g} \cdot \mathrm{cm}^{-3}\right]$.

In air, all nitrogen-containing phases reacted to tantalum oxide at $773 \mathrm{~K}$. In contrast, in nitrogen atmosphere anatase-type $\mathrm{TaON}$ undergoes a phase transition between 1073 and $1123 \mathrm{~K}$ to the baddeleyite-type $\beta-\mathrm{TaON}$ with a density of $11.0 \mathrm{~g} \cdot \mathrm{cm}^{-3}$. This phase is preserved after cooling to room temperature, indicating an irreversible phase transformation. No formation of $\gamma$-TaON was observed during these experiments.

The calculated relative Gibbs energies as a function of the temperature (Figure 4.6, right, VASP/PBE results) clearly show that $\delta-\mathrm{TaON}$ is thermodynamically unstable up to about $1600 \mathrm{~K}$, and a phase transition to $\beta-\mathrm{TaON}$ should occur at lower temperatures. Experimentally, however, the $\delta$ to $\beta$ phase transition is found between 1073 and $1123 \mathrm{~K}$ although $\Delta G$ is then much smaller compared to room temperature. Hence, kinetics is controlling the transition from $\delta$ to $\beta$.

In order to investigate the dynamic stability of $\delta$-TaON we calculated the phonon density of states (PDOS) at ambient pressure. As can be seen in Figure 4.7 the PDOS does not exhibit any imaginary modes. Hence, the dynamic stability of the phase is assured, and anatase-type $\mathrm{TaON}$ is classified as a metastable solid-state material.

For the calculation of absolute band positions with respect to the vacuum, it is necessary to perform two-dimensional calculations of the TaON surface in order to circumvent the self-interaction problem in the Ewald summation. Therefore, several low-index surfaces have been investigated by performing periodic slab calculations (C09/PBE0) 


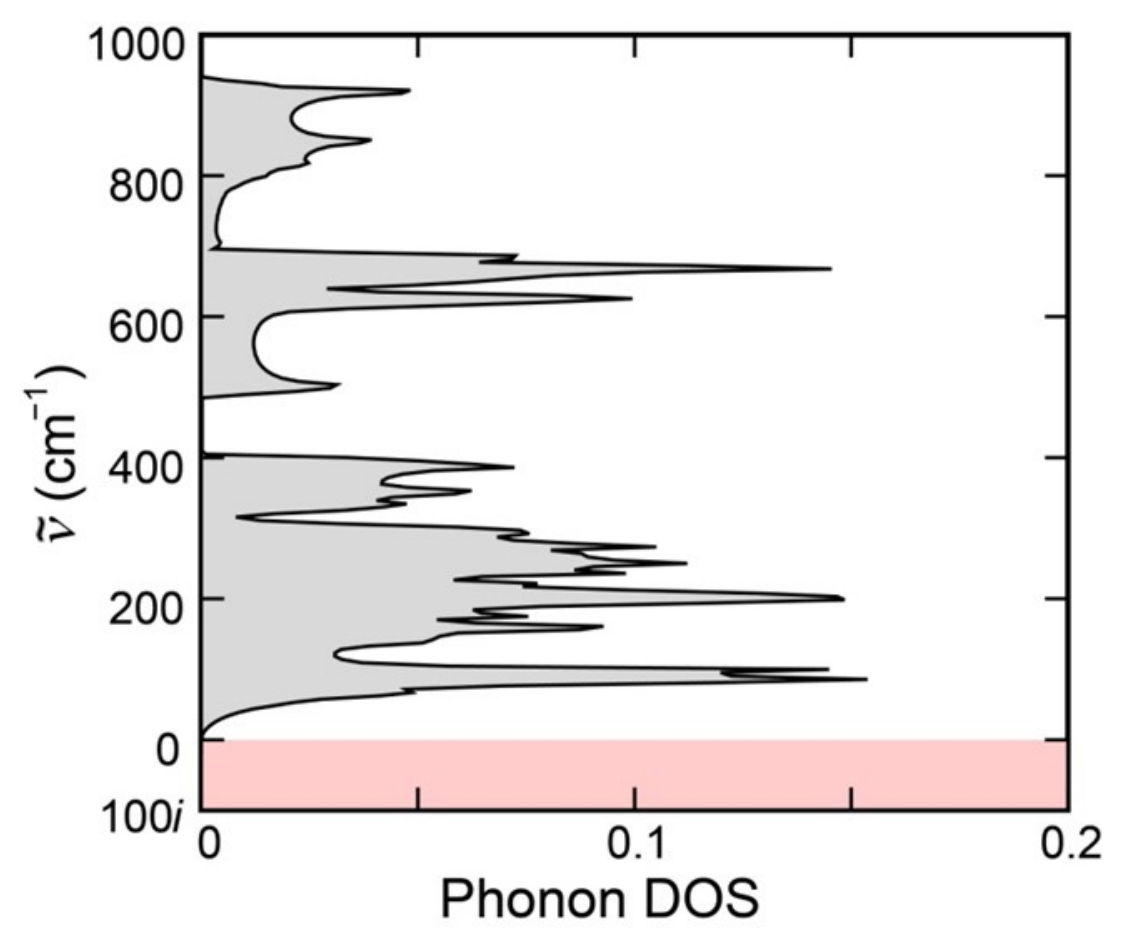

Figure 4.7.

Phonon density of states of $\delta$ - $\mathrm{TaON}$ at ambient pressure calculated via densityfunctional theory.

which are treated as truly two-dimensional systems in CRYSTAL. By calculating the surface energies $E_{\mathrm{S}}$ it was found that the $(100)$ surface is most stable $\left(E_{\mathrm{S}}^{\mathrm{PBE}}=1.1 \mathrm{~J} \cdot \mathrm{m}^{-2}\right.$, $\left.E_{\mathrm{S}}^{\mathrm{PBE} 0}=1.2 \mathrm{~J} \cdot \mathrm{m}^{-2}\right)$. The surface energies were converged for slab models consisting of eight or more stoichiometric layers. In order to obtain a value for the optical gap, we first calculated the quasiparticle gap using the GW0 approach for the $\delta$-TaON bulk system (VASP/PBE). After five iterations where only the single particle Green's function was updated whereas the Coulomb interaction was kept fixed, we obtained a value of $E_{\mathrm{g}}=3.2 \mathrm{eV}$ for the quasiparticle gap which agrees very well with the PBE0 result for the bulk. The subsequent BSE calculation gave an excitation energy for the first optical transition of $2.7 \mathrm{eV}$ which is in good agreement with the experimentally determined value for thin films of anatase-type $\mathrm{TaON}(2.4 \mathrm{eV})$.

To predict the applicability of $\delta-\mathrm{TaON}$ as a photocatalyst in redox reactions it is necessary to determine whether tabulated redox potentials lie in between the material's valence and conduction band edges. ${ }^{32}$ Therefore, we calculated the absolute values for the valence band maximum (VBM) and the conduction band minimum (CBM) according to

$$
E_{\mathrm{VBM}}=E_{\mathrm{VBM}}^{(100)}-\frac{1}{2} E_{\mathrm{g}}^{\mathrm{BSE}} ; \quad E_{\mathrm{CBM}}=E_{\mathrm{BGC}}^{(100)}+\frac{1}{2} E_{\mathrm{g}}^{\mathrm{BSE}}
$$


Here $E_{\mathrm{g}}^{\mathrm{BSE}}$ is the optical band gap in contrast to ref. 32 where the quasiparticle gap was used. This way we obtained the band edge energies $E_{\mathrm{VBM}}=-6.6 \mathrm{eV}$ and $E_{\text {СвM }}=-3.9 \mathrm{eV}$ with respect to the vacuum level. Thus, in a photocatalytical setup $\delta$ - $\mathrm{TaON}$ can possibly support redox reactions like the $\mathrm{H}_{2} \mathrm{O} / \mathrm{O}_{2}$ couple $(E=-5.7 \mathrm{eV}$, $p H=0$ ) that have potentials in this range.

\subsection{Conclusions}

We were successful in synthesizing a new polymorph of tantalum oxide nitride with anatase-type structure by an ammonolysis reaction. The measured density is higher than the one of the thermodynamically more stable $\gamma$-TaON phase exhibiting the $\mathrm{VO}_{2}(\mathrm{~B})$ structure. $\delta$-TaON is metastable and undergoes a phase transformation to baddeleyitetype $\beta$-TaON between 1073 and $1123 \mathrm{~K}$. The absolute band edge positions were calculated by combining the results from periodic slab calculations with the lowest optical excitation energy for the bulk crystal, obtained with the BSE method. The resulting band edge energies $\left(E_{\mathrm{VBM}}=-6.6 \mathrm{eV}, E_{\mathrm{CBM}}=-3.9 \mathrm{eV}\right)$ indicate that $\delta-\mathrm{TaON}$ is a promising photocatalytic material for redox reactions, e.g., water splitting. With the enormous interest in tantalum oxide nitride phases for solar fuel production via photo- or photoelectrochemical water splitting, additional work to prepare a phase-pure material is planned. Moreover, also the synthesis of a rutile-type metastable $\mathrm{TaON}$ phase, which is calculated to be at most $13 \mathrm{~kJ} \cdot \mathrm{mol}^{-1}(\mathrm{C} 09 / \mathrm{PBE} 0, T=0 \mathrm{~K})$ less stable than the here presented anatase-type phase, is ongoing work.

\subsection{Acknowledgements}

This work is supported by the German Science Foundation (DFG) within the priority programs SPP 1415 (T. L., N. B., C. R., T. B., R. D., M. L.) and SPP 1613 (A. F., M. L.). XRF analysis by Rafael Zubrzycki and N/O analysis by Brigitte Hahn are gratefully acknowledged. The authors thank Dr. Dennis Wiedemann for compiling the CIF file. Access to the TEM facilities at the ZELMI (TUB) and equipment funding by the DFG Excellenz Cluster UniCat are gratefully acknowledged. We appreciate support and provisioning of computational resources by the Paderborn Center for Parallel Computing. 


\subsection{References}

(1) Jansen, M.; Letschert, H. P. Nature 2000, 404, 980-982.

(2) Aguiar, R.; Logvinovich, D.; Weidenkaff, A.; Rachel, A.; Reller, A.; Ebbinghaus, S. G. Dyes and Pigments 2008, 76, 70-75.

(3) Lerch, M.; Lerch, J.; Hock, R.; Wrba, J. J. Solid State Chem. 1997, 128, 282-288.

(4) Hitoki, G.; Takata, G.; Kondo, J. N.; Hara, M.; Kobayashi, H.; Domen, K. Chem. Commun. 2002, 16, 1698-1699.

(5) Hara, M.; Hitoki, G.; Takata, T.; Kondo, J. N.; Kobayashi, H., Domen, K. Catalysis Today 2003, 78, 555-560.

(6) Brauer, G.; Weidlein, J. R. Angew. Chem. Int. Ed. 1965, 4, 875-875.

(7) Schilling, H.; Stork, A.; Irran, E.; Wolff, H.; Bredow, T.; Dronskowski, R.; Lerch, M. Angew. Chem. Int. Ed. 2007, 46, 2931-2934.

(8) Buslaev, Yu. A.; Safronov, G. M.; Pakhomov, V. I.; Glushkova, M. A.; Repko, V. P.; Ershova, M. M.; Zhukov, A. N.; Zhdanova, T. A. Neorg. Mat. 1969, 5, 45-48; Neorg. Mat., Int. Ed. Engl. 1969, 5, 37-39.

(9) Lumey, M.-W.; Dronskowski, R. Z. Anorg. Allg. Chem. 2003, 629, 2173-2179.

(10) Lumey, M.-W.; Dronskowski, R. Z. Anorg. Allg. Chem. 2005, 631, 887-893.

(11) Lowther, J. E. J. Phys. Rev. B 2005, 72, 172105-1-4.

(12) Woodhead, K.; Pascarelli, S.; Hector, A. L.; Briggs, R.; Alderman, N.; McMillan, P. F., Dalton Trans. 2014, 43, 9647-9654.

(13) Bredow, T.; Lumey, M.-W.; Dronskowski, R.; Schilling, H.; Pickardt, J.; Lerch, M. Z. Anorg. Allg. Chem. 2006, 632, 1157-1162.

(14) Schilling, H.; Lerch, M.; Börger, A.; Becker, K.-D.; Wolff, H.; Dronskowski, R.; Bredow, T.; Tovar, M.; Baehtz, C. J. Solid State Chem. 2006, 179, 2416-2425.

(15) Stork, A.; Schilling, H.; Wessel, C.; Wolff, H.; Börger, A.; Baehtz, C.; Becker, K.D.; Dronskowski, R.; Lerch, M.J. Solid State Chem. 2010, 183, 2051-2058.

(16) Suzuki, A.; Hirose, Y.; Oka, D.; Nakao, S.; Fukumura, T.; Ishii, S.; Sasa, K.; Matsuzaki, H.; Hasegawa, T. Chem. Mater. 2014, 26 (2), 976-981.

(17) Okubo, T.; Kakihana, M. Journal of Alloys and Compounds 1997, 256, 151-154. 
(18) Rodriguez-Carvajal, J. Abstracts of the Satellite Meeting on Powder Diffraction of the XVCongress of the IUCr 1990, 127.

(19) (a) Kresse, G.; Hafner, J. Phys. Rev. B 1993, 47, 558-561. (b) Kresse, G.; Hafner, J. Phys. Rev. B, 1994, 49, 14251-14269.

(20) (a) Kresse, G.; Furthmüller, J. Comput. Mater. Sci. 1996, 6(1), 15-50. (b) Kresse, G.; Furthmüller, J. Phys. Rev. B 1996, 54, 11169-11186.

(21) Blöchl, P. E. Phys. Rev. B 1994, 50(24), 17953-17979.

(22) Perdew, J. P.; Burke, K.; Ernzerhof, M. Phys. Rev. Lett. 1996, 77(7), 3865-3868.

(23) Togo, A.; Oba, F.; Tanaka, I. Phys. Rev. B 2008, 78 (13), 134106-1-9.

(24) Stoffel, R. P.; Wessel, C.; Lumey, M.-W.; Dronskowski, R. Angew. Chem. Int. Ed. 2010, $49(31), 5242-5266$.

(25) Birch, F. Phys. Rev. 1947, 71 (11), 809-824.

(26) Adamo, C.; Barone, V.J. Chem. Phys. 1999, 110, 6158-6170.

(27) Dovesi, R.; Saunders, V. R.; Roetti, R.; Orlando, R.; Zicovich-Wilson, C. M.; Pascale, F.; Civalleri, B.; Doll, K.; Harrison, N. M.; Bush, I. J.; D’Arco, P.; Llunell, M. CRYSTALO9 (CRYSTALO9 User's Manual), University of Torino, Torino, 2009.

(28) Andrae, D.; Häußermann, U.; Dolg, M.; Stoll, H.; Preuss, H. Theor. Chim. Acta 1990, 77, 123-141.

(29) Pascale, F.; Zicovich-Wilson, C. M.; Lopez, F.; Civalleri, B.; Orlando, R.; Dovesi, R. J. Comput. Chem. 2004, 25, 888-897.

(30) Zicovich-Wilson, C. M.; Pascale, F.; Roetti, C.; Saunders, V. R.; Orlando, R.; Dovesi, R. J. Comput. Chem. 2004, 25, 1873-1881.

(31) Baerends, E. J.; Gritsenko, O. V.; van Meer, R. Phys. Chem. Chem. Phys. 2013, 15, $16408-16425$.

(32) Caspary Toroker, M.; Kanan, D. K.; Alidoust, N.; Isseroff, L. Y.; Liao, P.; Carter, E. A. Phys. Chem. Chem. Phys. 2011, 13, 16644-16654.

(33) Perdew, J. P., Levy, M. Phys. Rev. Lett. 1983, 51, 1884-1887.

(34) Ramos, L. E.; Paier, J.; Kresse, G.; Bechstedt, F. Phys. Rev. B. 2008, 78, 195423-19. 
(35) Shannon, R. D.; Prewitt, C. T. Acta Crystallogr. Sect. B 1969, 25 (5), 925-946.

(36) Wolff, H.; Lerch, M.; Schilling, H.; Bähtz, C.; Dronskowski, R. J. Solid State Chem. 2008, 181, 2684-2689.

(37) Wolff, H.; Dronskowski, R. J. Comput. Chem. 2008, 29, 2260-2267.

(38) Lowther, J. E. Phys. Rev. B 2006, 73, 134110-1-8.

(39) Fang, C. M.; Orhan, E.; de Wijs, G. A.; Hintzen, H. T.; de Groot, R. A.; Marchand, R.; Saillard, J.-Y.; de With, G. J. Mater. Chem. 2001, 11, 1248-1252.

(40) Hollemann, A. F.; Wiberg, N. Lehrbuch der anorganischen Chemie, 102th ed., de Gruyter, Berlin, 2007.

(41) Shishkin, M.; Kresse, G. Phys. Rev. B 2006, 74, 035101-1-13.

(42) Shishkin, M.; Kresse, G. Phys. Rev. B 2007, 75, 235102-1-9.

(43) Fuchs, F.; Furthmüller, J.; Bechstedt, F.; Shishkin, M.; Kresse, G. Phys. Rev. B 2007, 76, 115109-1-8.

(44) Shishkin, M.; Marsman, M.; Kresse, G. Phys. Rev. Lett. 2007, 99, 246403-1-4. 


\subsection{Supporting Information}

Table 4.3. Gaussian-type basis sets for $\mathrm{Ta}, \mathrm{O}$, and $\mathrm{N}$.

\begin{tabular}{|c|c|c|c|}
\hline Element & Shell type & Exponent & Coefficient \\
\hline \multirow[t]{16}{*}{$\mathrm{Ta}(\mathrm{SD} 60 \mathrm{MWB})$} & 5s & 13.92894522 & -0.65530133 \\
\hline & & 11.99334000 & 0.99999851 \\
\hline & & 5.13783577 & -0.75340391 \\
\hline & $6 s$ & 0.81369698 & 1.00000000 \\
\hline & $7 \mathrm{~s}$ & 0.20617834 & 1.00000000 \\
\hline & $5 p$ & 7.39668050 & 0.58299598 \\
\hline & & 5.71622490 & -0.99750066 \\
\hline & $6 p$ & 1.11480608 & 0.53922059 \\
\hline & & 0.48684871 & 0.43278257 \\
\hline & $7 \mathrm{p}$ & 0.20000020 & 1.00000000 \\
\hline & $5 \mathrm{~d}$ & 3.89501783 & -0.07125693 \\
\hline & & 1.54623255 & 0.18750222 \\
\hline & & 0.78972687 & 0.33933435 \\
\hline & & 0.39161871 & 0.46423064 \\
\hline & $6 \mathrm{~d}$ & 0.20001481 & 1.00000000 \\
\hline & $4 f$ & 0.69700000 & 1.00000000 \\
\hline \multirow[t]{17}{*}{$\mathrm{O}$} & $1 \mathrm{~s}$ & 17236.81829238 & 0.00074182 \\
\hline & & 2751.75465497 & 0.00535982 \\
\hline & & 644.13976274 & 0.02693106 \\
\hline & & 186.54606980 & 0.10368114 \\
\hline & & 62.05370174 & 0.30631113 \\
\hline & & 22.40522705 & 0.63919506 \\
\hline & & 8.63211071 & 0.69861249 \\
\hline & & 3.43665812 & 0.23444923 \\
\hline & $2 s$ & 31.23086387 & -0.03031382 \\
\hline & & 8.75022651 & -0.16427606 \\
\hline & & 0.99708039 & 0.97908082 \\
\hline & $3 s$ & 0.29679220 & 1.00000000 \\
\hline & $2 \mathrm{p}$ & 37.97017643 & 0.01498951 \\
\hline & & 8.81023497 & 0.09235816 \\
\hline & & 2.57513767 & 0.29875716 \\
\hline & & 0.80224337 & 0.49916591 \\
\hline & $3 p$ & 0.23077580 & 1.00000000 \\
\hline
\end{tabular}




\begin{tabular}{llll}
\hline Element & Shell type & Exponent & Coefficient \\
\hline $\mathrm{O}$ & $3 \mathrm{~d}$ & 0.28447631 & 1.00000000 \\
$\mathrm{~N}$ & $1 \mathrm{~s}$ & 19610.14142999 & 0.00067103 \\
& 2918.28119664 & 0.00524937 \\
& 662.82669961 & 0.02721870 \\
& 188.48972830 & 0.10851369 \\
& 61.86476194 & 0.33759047 \\
& 22.40189484 & 0.75710716 \\
& 8.70806179 & 1.04888702 \\
& 3.43054032 & 0.59027045 \\
& 19.83643370 & 0.75107092 \\
& 5.74154083 & 3.14684949 \\
& & 0.85051883 & -14.22933913 \\
& & 0.26704755 & 1.00000000 \\
& & 40.95912588 & 0.01123324 \\
& & 9.12783302 & 0.08265355 \\
& $2 \mathrm{p}$ & 2.53467765 & 0.31399797 \\
& & 0.78249957 & 0.62944112 \\
& & 0.20016341 & 1.00000000 \\
& 0.51431751 & 1.00000000 \\
\hline
\end{tabular}

